\title{
LETTERS—CONCISE RESEARCH REPORTS \\ Analysis of the Impact of Step 1 Scores on Rank Order for the NRMP Match
}

KEY WORDS: USMLE; resident ranking; NRMP match; neural network.

J Gen Intern Med 36(11):3582-3

DOI: $10.1007 / \mathrm{s} 11606-020-06370-4$

(C) Society of General Internal Medicine 2021

\section{INTRODUCTION}

The United States Medical Licensing Examination (USMLE) Step exams are designed to assess a physician's abilities to apply knowledge, concepts, and principles important to the provision of patient care. ${ }^{1}$ As such, they are used by state medical boards in deciding the disposition of license applications.

These standardized tests have also often been used as part of the resident selection process. The USMLE, and others, have been concerned about the over reliance of programs on tests not intended for this purpose. The USMLE has then recently announced that they will be changing the reporting of Step 1 scores to Pass/Fail.

The question is then whether this will affect the rank order for residency applicants.

\section{METHODS}

The resident selection committee for Internal Medicine at East Tennessee State University met as usual and selected a rank order for the residents for the incoming class of 2020. This procedure was unchanged from prior years. Information available to the ranking committee included Step 1 and Step 2 scores, interview scores (compiled from the interviews with categories such as fit, academic abilities, letters of reference), scale (from the interviews, range from rank Top $10 \%$ to Do Not Rank), sex, medical school, and graduation date. For students who had taken both Comlex and USLME exams, only the USMLE results were considered. For those who only took the Comlex, conversion to a comparable USMLE score

Received July 13, 2020

Accepted November 25, 2020

Published online January 7, 2021 was performed. ${ }^{2}$ Approximately 1 month later, the announcement was made that Step 1 will be moving to Pass/Fail.

A deep neural network was created to model the rank order list. Categorical items such as sex or medical school location were converted to a series of attributes through one hot encoding. This model was trained on the actual rank order list. Using this model, a rank order was created that was close to the original. This model was then used to create a rank order eliminating the effect of Step 1 by changing the value of each applicant's Step 1 score to the mean. The results were then compared to the predicted rank list using Step 1 scores.

A separate multiple linear regression was performed to estimate the impact of each feature (attribute) on the rank order.

\section{RESULTS}

The neural network was trained on the current list and reached a mean accuracy error of 4 . Comparing the match order lists with and without Step 1 scores yielded a correlation coefficient of 0.983 with a $p$ value of $1.64 \times 10^{-85}$, showing a very high degree of correlation between the lists with and without Step 1.

The linear regression showed the top four attributes by impact on the rank order were scale (estimated rank by interviewers), interview score, Step 2 score, and graduation year

Table 1 Since 1 is the top rank, negative items move the applicant up the rank order list

\begin{tabular}{ll}
\hline \hline Factor & Correlation coefficient \\
\hline Interview score & -59.67 \\
Scale & -65.03 \\
Graduation date & -20.48 \\
Step 1 score & 1.42 \\
Step 2 score & -25.28 \\
MD degree & -3.51 \\
DO degree & 1.92 \\
MBBS degree & 3.71 \\
MBBCH degree & -2.11 \\
Male & 2.63 \\
Female & -2.63 \\
Regional Medical School & -13 \\
US Medical School & -3.4 \\
Caribbean Medical School & 8.65 \\
Other Medical School & 7.71 \\
\hline
\end{tabular}


(preference given to more recent graduates). Step 1 score had the lowest independent impact of any of the 15 attributes. Table 1 contains the correlation coefficients (cc) for each of the factors. A factor with a cc or 0 would have no impact. CCs with negative values would move the applicant up the rank order, and cc's with positive values move the applicant down the rank order list.

\section{DISCUSSION}

Based on the model results, it appears that USMLE Step 1 scores do not have a significant effect on the rank order of applicants to our Internal Medicine categorical residency program. Other factors appear to have a greater impact.

Limitations to this study are numerous. The model applies to a single year in a single Internal Medicine program. Before a person can be ranked, they must be interviewed, and the decision to interview likely includes Step 1 scores. Interviewers also are aware of Step 1 scores and this may influence the interview score and scale scores.

Jeffrey A. Summers, MD FACP FSSCI ${ }^{1,2}$

${ }^{1}$ Department of Internal Medicine, Quillen College of Medicine, East Tennessee State University, Johnson City, TN, USA

${ }^{2}$ Kingsport, TN, USA
Corresponding Author: Jeffrey A. Summers, MD FACP FSSCI; Kingsport, TN, USA (e-mail: summersj@etsu.edu).

\section{Compliance with Ethical Standards:}

Conflict of interest: There are no conflicts of interest for this publication.

\section{REFERENCES}

1. United States Medical Licensing Examination $\circledR^{\circledR}$ https://www.usmle.org/: Last access 3/31/2020.

2. Slocum PC, Louder JS. How to predict USMLE scores from COMLEX-USA scores: a guide for directors of ACGME-accredited residency programs. J Am Osteopath Assoc. 2006; 106(9): 568-9.

Publisher's Note: Springer Nature remains neutral with regard to jurisdictional claims in published maps and institutional affiliations. 